\title{
Camenellan tommotiids from the Cambrian Series 2 of East Antarctica: Biostratigraphy, palaeobiogeography, and systematics
}

Thomas M. Claybourn, Christian B. Skovsted, Marissa J. Betts, Lars E. Holmer, Lucy Bassett-Butt, and Glenn A. Brock

Acta Palaeontologica Polonica 66 (1), 2021: 207-229 doi:https://doi.org/10.4202/app.00758.2020

Cambrian Series 2 shelly fossils from thick carbonate successions in East Antarctica have received limited systematic treatment through the 20th century. Described here are the East Antarctic camenellan tommotiids from the Shackleton Limestone in the Central Transantarctic Mountains and the Schneider Hills limestone in the Argentina Range. This material comes from both newly sampled collections and incompletely described material from older collections. The assemblage supports correlation to the Dailyatia odyssei Zone and Pararaia janeae Trilobite Zone of South Australia, with the newly examined specimens of Dailyatia decobruta from the Shackleton Limestone providing direct correlation to the Mernmerna Formation of the Ikara-Flinders Ranges and White Point Conglomerate of Kangaroo Island. These East Antarctic assemblages include five species referred to Dailyatia, in addition to an undetermined kennardiid species and fragments of the problematic Shetlandia multiplicata. The results further corroborate the notion that fossiliferous carbonate clasts found on King George Island were sourced from the same carbonate shelf as the Shackleton Limestone, with the taxon S. multiplicata found in both units. The Schneider Hills limestone in the Argentina Range has yielded sclerites of Dailyatia icari sp. nov., currently only known from this location.

Key words: Tommotiida, Dailyatia, biostratigraphy, palaeobiogeography, Cambrian, Central Transantarctic Mountains.

Thomas M. Claybourn [thomas.claybourn@ @dr.mqu.edu.au], Department of Earth Sciences, Palaeobiology, Uppsala University, Villav. 16, SE-75236, Uppsala, Sweden; Department of Biological Sciences, Macquarie University, North Ryde, Sydney, NSW, 2109, Australia. Christian B. Skovsted [christian.skovsted@nrm.se ], Department of Palaeobiology, Swedish Museum of Natural History, Box 50007, SE 10405 Stockholm, Sweden; Early Life Institute and Department of Geology, State Key Laboratory for Continental Dynamics, Northwest University, Xi'an 710069, China. Marissa J. Betts [marissa.betts@une.edu.au], Palaeoscience Research Centre, School of Environmental and Rural Science, University of New England, Armidale, NSW, 2351, Australia; Early Life Institute 
and Department of Geology, State Key Laboratory for Continental Dynamics, Northwest University, Xi'an 710069, China. Lars E. Holmer [1ars.holmer@pal.uu.se ], Department of Earth Sciences, Palaeobiology, Uppsala University, Villav. 16, SE-75236, Uppsala, Sweden; Early Life Institute and Department of Geology, State Key Laboratory for Continental Dynamics, Northwest University, Xi'an 710069, China. Lucy Bassett-Butt [1bassettbutt@gmail.com], Department of Earth Sciences, Palaeobiology, Uppsala University, Villav. 16, SE-75236, Uppsala, Sweden. Glenn A. Brock [glenn.brock@mq.edu.au], Department of Biological Sciences, Macquarie University, North Ryde, Sydney, NSW, 2109, Australia; Early Life Institute and Department of Geology, State Key Laboratory for Continental Dynamics, Northwest University, Xi'an 710069, China.

This is an open-access article distributed under the terms of the Creative Commons Attribution License (for details please see creativecommons.org), which permits unrestricted use, distribution, and reproduction in any medium, provided the original author and source are credited. 